\title{
THE COMMUNITY INTEREST COMPANY: MORE CONFUSION IN THE QUEST FOR LIMITED LIABILITY?
}

\author{
Stuart R. Cross, Department of Law, University of Dundee
}

\section{INTRODUCTION}

In the United Kingdom there is at present a strong culture of support for easy access to legal forms which provide the protective benefit of limited liability to those involved in the conduct of the affairs of the organisation in question ${ }^{1}$. A new vehicle in the form of the limited liability partnership was introduced in $2000^{2}$ with an express aim of providing access to limited liability status for individuals and firms which had hitherto been largely restricted to using conventional unlimited liability partnership structures. The UK Company Law Review (CLR) also sought to make the limited liability company more attractive to smaller businesses. ${ }^{3}$ This culture is now also clearly evident in respect of the not- for- profit sector. The report by the Performance and Innovation Unit of the Cabinet Office into the not-for-profit sector ${ }^{4}$ proposed the creation of a new legal form for charities: the Charitable Incorporated Organisation (CIO). That proposal has been followed by a recommendation that a new form of social enterprise organisation called a Community Interest Company (CIC) should be created. ${ }^{5}$ The proposal in respect of the CIC has now been confirmed in the Government's legislative proposals for the 2003-2004 parliamentary session and a bill containing the requisite provisions for the creation of the CIC has now been introduced in the House of Lords. ${ }^{6}$ This article considers the recent development of arguments within the United Kingdom for new organisational forms in the

1 See, for example, paragraph 1.27 of The Company Law Review Steering Group Final Report (URN 01/942 and 943) (DTI, 2001) (hereafter referred to as the "Final Report") which states that "It is crucial that the law provides an optimal framework for the establishment, efficient operation and development and growth of ... companies".

2 Limited Liability Partnerships Act 2000.

3 See paragraph 1.3 of the White Paper, "Modernising Company Law" (Cm. 5553) which followed the publication of the Final Report. This reflects the stance taken in the Final report and states that "Company law should make it easy to start and run businesses".

4 Private Action, Public Benefit - A Review of Charities and the Wider Not For Profit Sector, (London, Strategy Unit Report, September 2002, also published electronically and to be found at www.strategy-unit.gov.uk/2002/charity/report /index.htm (hereafter referred to as "Private Action, Public Benefit").

5 The proposal is contained in a consultation paper "Enterprise for Communities Proposals for a Community Interest Company" published by the DTI, HM Treasury and the Home Office in March 2003 (hereafter referred to as "Enterprise for Communities").

6 The Companies (Audit, Investigations and Community Enterprise) Bill [HL] (referred to hereafter as the" Companies Bill") was introduced in the House of Lords on $3^{\text {rd }}$ December 2003, had its second reading on $8^{\text {th }}$ January 2004 and completed the Grand Committee stage on $29^{\text {th }}$ March 2004. 
not-for-profit sector and the resulting legislative proposals for such organisations against the backdrop of significant issues which have arisen in respect of the most recently introduced legal form, the LLP. The article considers in detail the proposed structure of the CIC, identifies a number of practical issues arising from the proposals and considers whether lessons may be learnt from the process which led to the Limited Liability Partnerships Act 2000. The article concludes that while there may be arguments which appear to justify ease of access to limited liability status in the form of dedicated legal forms such as the CIC, the manner by which access to and the organisations through which such status is to be offered may give rise to confusion both in the minds of those dealing with such organisations and those responsible for running them as to which organisational form is best suited to their needs.

\section{RECENT DEVELOPMENTS IN LEGAL FORM}

\section{The LLP}

The most recently introduced legal form in the United Kingdom is the Limited Liability Partnership (LLP). ${ }^{7}$ While the LLP is only available for use by those carrying on business in the United Kingdom ${ }^{8}$ and is therefore not directly available for not-for-profit organisations, the manner by which the LLP came into existence and the legislative approach inherent in the LLPA are both informative as to how the CIC, as the first legal form to be proposed after the creation of the LLP, might be received and how it might impact on those who contemplate using it as a vehicle for incorporation..

The LLP was introduced into the United Kingdom primarily to address the concerns and meet the perceived requirements of the accountancy and other professional partnerships ${ }^{9}$ where the potentially unlimited liability associated with the partnership form used by such organisations was increasingly being criticised by such users as inherently unsatisfactory. However, concerns were raised from the outset as to how well founded the LLP was in terms of the reasoning and preparation which was undertaken before its introduction. In reviewing the early proposals for the LLP the House of Commons Select Committee on Trade and Industry remarked that "neither of the two DTI papers contained anything approaching a full and considered analysis of the issues addressed by the Bill". ${ }^{10}$ At the same time the Department of Trade and Industry was undertaking a wide ranging review of company law and the Law Commissions in England and Scotland were embarking on a joint review of the law of partnership. ${ }^{11}$ The LLP was not included as an item for consideration in either review process and as a result it appeared to be shaped

7 Introduced by the Limited Liability Partnerships Act 2000 (LLPA).

8 S.2 of the LLPA specifies that a limited liability partnership can only be formed by two or more persons "carrying on a lawful business with a view of profit".

9 For a detailed discussion of the history of the LLP in the United Kingdom see J. Freedman and V. Finch, "Limited Liability Partnerships: Have Accountants Sewn Up the 'Deep Pockets' Debate?”, [1997] J.B.L 387.

10 Paragraph II, 6 of the proceedings of the Fourth Committee of the Select Committee on Trade and Industry which met on $16^{\text {th }}$ February 1999.

11 The Law Commissions have now reported. "Partnership Law", Cm.6015, SE/2003/299. 
more by reference to the particular needs and desires of the professional bodies who sought its creation rather than as part of a broader process looking at the evolution and development of business forms in the United Kingdom. The resulting structure of the LLP is characterised by the adoption of elements of existing rules and principles of both partnership and company law in the United Kingdom. The LLPA is a very short piece of legislation extending to only nineteen sections and two brief schedules, with many substantive principles and the clearest examples of deemed application of existing company and partnership law being found in subsequent regulations. $^{12}$ Despite the adoption of rules and principles from both company and partnership law the LLP is inherently corporate in nature and character. $^{13}$ It has been argued that this process of adopting a corporate character for the LLP which is overlaid with partnership law principles gives rise to a potential weakness in the LLP. Freedman and Finch ${ }^{14}$ argue that the adoption of rules and principles from two conceptually different legal forms has practical and legal consequences ${ }^{15}$ which give rise to "serious conceptual confusion". ${ }^{16}$ One of the areas where Freedman and Finch identify an example of this conceptual confusion is in respect of the position of members of an LLP and the nature and extent of the limited liability protection which is actually afforded to such members. ${ }^{17}$ Freedman and Finch argue that particular difficulties arise in connection with what is referred to as 'the clawback'. In its originally proposed form the LLP would only have been available to regulated professions ${ }^{18}$ and as part of the price for receiving the broad benefit of limited liability, members of an LLP would have greater liability for their personal wrongs than would otherwise have been the case with a conventional limited liability company. The 'clawback' is the mechanism devised to provide this greater degree of creditor protection. The clawback is introduced by means of a new section 214A of the Insolvency Act 1986 and its purpose is to provide some degree of protection against members siphoning off funds in the event of insolvency. The difficulty Freedman and Finch identify in respect of the clawback arises from the manner in which it has been implemented. Section 214A of the Insolvency Act 1986 is closely modelled on the existing section 214 of that Act. Conceptually, however, the section deals with an entirely different issue whereby members effectively place themselves in a preferential position. The concern expressed by Freedman and Finch is that there will be considerable uncertainty as to how the clawback will be interpreted by the judiciary with potentially adverse consequences for creditors of an LLP. The

12 The Limited Liability Partnerships Regulations 2001(SI2001/1090).

13 S.1 (2) of the LLPA states that the LLP is a body corporate separate from its members.

14 See J. Freedman and V. Finch, "The Limited Liability Partnership: Pick and Mix or Mix-Up", [2002] J.B.L 475 (referred to hereafter as "Freedman and Finch").

15 Freedman and Finch n.13 above at pp. 482-483.

16 Freedman and Finch n.13 above at p.483.

17 Freedman and Finch n.13 above at pp.483-488.

18 Both the original consultation papers on the LLP raised the question of whether it should be restricted in availability to regulated professions. The title of the first consultation paper DTI, "Limited Liability Partnerships-A New Form of Business Association for Professionals" (Consultation Paper URN 98/874) clearly anticipated that availability would be restricted. 
potential problem identified $^{19}$ is that creditors may have risk disproportionately transferred to them as a result of possible judicial interpretation of section 214A. If the courts take a stance which favours trading through difficulties and as a result are less than strict with members, then creditors have to assume a greater degree of risk. Similarly, if the courts adopt a differing interpretation of the clawback which is strict in its treatment of members they will be encouraged to leave their LLP when difficulties emerge, which again has an adverse impact on creditors. Freedman and Finch argue that the uncertainty for creditors associated with the clawback mechanism is likely to encourage them to deal with the potential risks by possibly increasing loan rates for LLPs and encouraging borrowers to use existing and understood legal forms such as the limited liability company.

The introduction of the LLP has therefore been accompanied by at least two substantive grounds for criticism. Firstly, the very reason for the introduction of the LLP was not based on a clearly reasoned analysis as to why a new legal form was required as opposed to the use of existing organisational structures which might have been capable of development to meets the identifiable needs of those who sought the introduction of the LLP. Secondly, the impact of the clawback mechanism on creditors is at best uncertain and may influence the approach of creditors in their dealings with LLPs and have potentially adverse consequences for creditors in the event of insolvency. Now that there are proposals to introduce another legal form so rapidly after the introduction of the LLP it is important to consider the CIC proposals in detail and assess whether similar issues are likely to arise in respect of the CIC.

\section{THE COMMUNITY INTEREST COMPANY}

\section{Background}

In September 2002 the Strategy Unit of the Cabinet office published a review of the charities and wider not-for-profit sector. The review, Private Action, Public Benefit ${ }^{20}$ considered the existing range of legal forms taken by charities and other not-for -profit organisations. In chapter five ${ }^{21}$ of Private Action, Public Benefit the first reference is made to CICs. In very brief terms it is argued that:

“. . companies legislation was not designed with the needs of smaller scale community-based social enterprises in mind. Problems include the fact that there is no entrenchment of the non-profit distributing nature of the organisation, nor the devotion of assets to a public purpose: that the Company limited by guarantee does not allow access to equity; and that the company "brand" is almost exclusively associated with profit-making." 22

Having drawn these conclusions the review recommended:

19 Freedman and Finch n.13 above at pp.502-511.

20 Supra, $\mathrm{n} 4$.

21 Private Action, Public Benefit, p.53.

22 Private Action, Public Benefit, para.5.20 at p.53. 
“. . . the establishment of a Community Interest Company ("CIC"), drawing as appropriate on company law, but with certain additional constraints and features which make it suitable for use by small scale community-based not-for-profit social enterprises familiar with the company form." 23

Following Private Action, Public Benefit the Department of Trade and Industry issued a consultation paper ${ }^{24}$ on $26^{\text {th }}$ March 2003 and the period for consultation closed on $18^{\text {th }}$ June 2003 .

Following the consultation exercise a report ${ }^{25}$ was issued by the DTI on $22^{\text {nd }}$ October 2003 and finally, the Companies Bill, containing proposals to create the CIC was introduced into the House of Lords on $3^{\text {rd }}$ December 2003.

\section{Features of the CIC}

\section{(a) A New Type of Company}

Part 2 of the Companies Bill contains the proposals for creation of the CIC. The CIC itself may be distinguished from the LLP in respect of the novelty of legal form. The LLP is an entirely new species of legal form which has a strongly corporate character with features of a partnership but which is entirely distinct from both the company and the partnership. The CIC will not be a new legal form in the pure sense but will take the form of a new species of company. ${ }^{26}$ The nature of the CIC as a company is further defined by the Companies Bill which specifies that a CIC may take the form of a company limited by guarantee or a company limited by shares ${ }^{27}$ and that even if formed for purposes which are charitable the CIC is not to be treated as charitable. ${ }^{28}$ The CIC can therefore be distinguished from the LLP in terms of possible issues arising from the creation of a new legal form de novo. As a form of company the CIC will be subject to the application of existing principles of company law. By comparison with the approach adopted in respect of the LLP this structure has the benefit of a level of certainty for potential users, advisers and the judiciary who, when dealing with CIC's, will simply look to existing principles of company law on most routine matters. ${ }^{29}$ Nonetheless, the CIC is novel and will be the subject of a number of principles and rules set out in the Companies Bill which do not exist in UK company law at present and an additional tier of regulation managed and implemented by a new regulator known as the Regulator of

23 Private Action, Public Benefit, para.5.21 at p.53.

24 "Enterprise For Communities-Proposals for a Community Interest Company", DTI, URN 02/1460

25 "Enterprise For Communities: Proposals For A Community Interest CompanyReport on the public consultation and the government's intentions", DTI URN $03 / 1344$.

${ }^{26}$ Companies Bill, Clause 23(1).

27 Companies Bill, Clause 23(2).

28 Companies Bill, Clause 23(3) (a).

29 In Enterprise for Communities this approach was outlined by the DTI and it was suggested that CIC's “. . . will follow the same incorporation and reporting procedures as other companies, and their directors and members will have the same rights and duties." Enterprise for Communities, para.15. 
Community Interest Companies. ${ }^{30}$ The most obvious manifestation of the new regulatory regime is the community interest test which any proposed CIC will have to satisfy before it may be registered as a CIC.

\section{(b) The Community Interest Test}

Before a CIC can be incorporated (or an existing company's status changed to permit it to operate as a CIC) it is proposed that it must satisfy a preliminary assessment as to whether it complies with what is referred to as the Community Interest Test. The most important function to be undertaken by the Regulator in the proposals for the CIC will be the determination as to whether or not the proposed company satisfies the proposed test. ${ }^{31}$ The Community Interest Test was first proposed in the DTI's Enterprise for Communities consultation paper but the discussion within that paper as to the underlying rationale behind the introduction of the test is not extensive. It is simply stated that:

"Public and community interest is the defining factor at the heart of the CIC. To ensure that CICs are focussed on this, the regulator will need to apply a robust test at the time of registration". ${ }^{32}$

The consultation paper elaborates on this basic premise by suggesting that:

"To become a CIC, an organisation will have to satisfy the regulator that its purposes could be regarded by a reasonable person as being beneficial to the community or wider public benefit". 33

Despite the brevity of the discussion on the issue at the consultation stage and the apparent absence of any discussion as to whether the adoption of a preliminary scrutiny mechanism was the only means of regulating access to CIC status, the Community Interest Test is the access mechanism which has been proposed. For those wishing to incorporate a CIC the proposed procedure appears to be relatively straightforward. The documents which are presently required by the Registrar of Companies for incorporation of a company must be prepared ${ }^{34}$ and submitted to the Registrar of Companies along with any other prescribed formation documents. These documents are then to be forwarded to the Regulator ${ }^{35}$ who will apply the Community Interest Test. If the documents submitted to the Regulator evidence compliance with the test the Regulator notifies the Registrar of Companies that this is the case, the company then proceeds to be registration ${ }^{36}$ and a certificate of incorporation will be issued which contains a statement to the effect that the company is a community interest company. ${ }^{37}$ If the Regulator decides that the documents submitted do not provide a basis to confirm

Companies Bill, Clause 24(1), hereafter referred to as "the Regulator".

Companies Bill, Clause 32.

Enterprise for Communities, para.16.

Enterprise for Communities, para.17.

34 Companies Bill, clause 33. The documents required are specified in s.10 of the Companies Act 1985.

35 Companies Bill, clause 33(3) (a).

36 Companies Bill, clause 33(7).

37 Companies Bill, clause 33(8). 
compliance with the Community Interest Test the subscribers to the memorandum of association submitted to the Regulator are entitled to appeal to another official referred to in the Companies Bill as the Appeal Officer. ${ }^{38}$ The function of the Appeal Officer is simply stated in the Companies Bill as being the determination of appeals against decisions and orders of the Regulator. ${ }^{39}$ For existing companies seeking recognition there are provisions which are designed to ensure that alterations to existing memoranda and articles of association and names are such that they too must comply with the Community Test.

There are a number of issues which arise in respect of the approach to admission to CIC status on the basis of the Community Interest Test. The first issue to consider is whether the approach adopted is the only or most effective approach which could have been adopted. The DTI consultation process offered no alternative approaches and in Enterprise for Communities, the Community Interest Test was the only mechanism discussed. In structural terms the adoption of the Community Interest Test has some parallels with the approach adopted in respect of charities in the United Kingdom whereby, irrespective of jurisdiction, charitable status is adjudicated upon by one body ${ }^{40}$ and organisational status may be dealt with by another. Thus, for example, in Scotland promoters of a charitable organisation may incorporate a company but that company will only be recognised as a charity once its purposes have been recognised as charitable by the Inland Revenue. This two stage process can be recognised in the slightly differing but nonetheless consistent approach of the Community Interest Test. Where the two approaches differ is in respect of the consequences which flow from recognition. Recognition as a charity is directly linked to a state concession in the form of relief from taxation. This relief is an inherent justification for the scrutiny process which affords recognition of charitable status. There is no similar concession from the state to CICs and, apart from the assertion in Enterprise for Communities that "public and community interest is the defining factor at the heart of the CIC", ${ }^{41}$ there is no clearly convincing alternative public policy argument adduced in the consultation process to the effect that the regulatory approach proposed is the only, or indeed, the most appropriate recognition mechanism. There are a number of alternatives. The present process for incorporation of companies in the United Kingdom recognises the various types of companies which exist. Existing companies legislation recognises differences in the ways differing types of companies are regulated and the levels of accountability to which they are subjected. ${ }^{42}$ One alternative to the

38 Clause 25 of the Companies Bill specifies that there is to be an officer known as the Appeal Officer who is to be appointed by the Secretary of State.

39 Companies Bill, clause 25.

40 In England and Wales by the Charity Commission and in Scotland the Inland Revenue.

41 Enterprise for Communities, para. 17.

42 The approach to company audit requirements is a clear example. In the 1980's there was a general move to review the regulatory burden imposed on small and medium sized companies in particular (for a good general discussion of the issues involved see Freedman and Goodwin, 'The Statutory Audit and the Micro Company - An Empirical Investigation' [1993] J.B.L 105. The debate resulted in 1994 in the abolition of the audit requirement for companies with a turnover of 
regulatory approach proposed in the Companies Bill would have been to require a formal declaration as part of the incorporation process that the company was being incorporated for community interest purposes. The initial declaration at the formation stage would be supported by repetition in the annual return. Failure to declare community status in the annual return would result in the company no longer being considered to be a community interest company. If this approach is considered to be too light in regulatory terms more robust mechanisms can be identified which are still consistent with the present approach of UK company law and which do not require the introduction of an entirely new regulatory regime. The elective regime is one such possibility. This regime provides companies with a mechanism whereby they may elect to structure certain of their activities in a manner which they consider to be efficient and which may relieve them of certain regulatory burdens ${ }^{43}$ Extension of the elective regime to include adoption of CIC status, accompanied by annual declarations confirming the retention of that status would be another means whereby the unique identity of a company as a community interest company could be recognised. What the consultation process, Enterprise for Communities and the Companies Bill fail to identify is the fundamental reason why the Community Interest Test and the Regulator are the only and most effective mechanisms which should be adopted.

The second issue to address in connection with the Community Interest Test is the very nature of the test itself. The test is stated in the Companies Bill as follows:

"A company satisfies the community interest test if a reasonable person might consider that its activities are being carried on for the benefit of the community". ${ }^{44}$

There is no significant elaboration in the Companies Bill as to what may be construed to be in the public interest but the bill clearly anticipates that regulations may be forthcoming which will provide guidance as to what activities might constitute community benefit. ${ }^{45}$ There exists the clear potential for uncertainty and confusion with the proposed formulation. If it is anticipated that regulations will be promulgated which will offer guidance as to what constitutes community benefit then it is unlikely that there will be a rush to seek CIC status until the activities which might give rise to recognition have been clarified. Another concern relates to the potential overlap in definitions. The reasonable person test for community benefit activities may be confused with the existing public benefit test for charitable organisations. The matter may become even more complicated if definitions within the charitable sector are revised. ${ }^{46}$ Some guidance has been given as

less than $£ 90,000$ (see the Companies Act 1985 (Audit Exemption Regulations 1994, SI 1994/1935). The present threshold is now $£ 1,000,000$ (see the Companies Act 1985 (Audit Exemption) (Amendment) Regulations 2000, SI 2000/1430).

43 Private companies may choose not to comply or observe certain provisions of the companies legislation if they pass an elective resolution in accordance with section 379A of the Companies Act 1985.

44 Companies Bill, clause 32(3).

45 Companies Bill, clause 32(4).

46 Separate Charities Bills are being consulted on for England and Wales and Scotland. The proposals for the Scottish bill were announced after two high 
to what the Government anticipates will inform the Regulator in assessing the reasonable person test. In the report ${ }^{47}$ on the public consultation on Enterprise for Communities the Government outlined its intentions on the test and detailed three features which will presumably be included in any regulations to be promulgated on the basis of the mechanism set out in clause 32(4) of the Bill. The three elements are as follows: ${ }^{48}$

"(a) Objective.

It is anticipated that the Regulator will base the assessment of community interest on what a reasonable person's assessment of the applicant's purposes would be and not on the regulator's interpretation;

(b) Transparent

Guidance will be published on the test and there will be an appeal process against decisions made by the Regulator; and

(c) Scope

The test is to be materially wider than the existing charitable test of public benefit."

Elements a) and b) offer little further illumination on how the test will be construed and applied by the Regulator. The fact that the scope of the test is to be materially wider than the existing charitable public benefit is significant but does not at this stage provide the level of certainty which will be sought by those contemplating the adoption of CIC status. The baseline definition of 'public benefit' is itself the subject of review in a charitable context and may become broader than is presently the case. This in turn would imply that the formulation of community interest could be construed even more broadly than might even be contemplated at present. If the criteria applied in determining community interest become too broad and diffuse there is a real risk that the credibility of the new CIC structure will be undermined and the necessity for a regulated admissions structure will become questionable. There will be a very delicate balance to be struck between the desire for the flexible application of relatively broad criteria which will permit access to CICs to a broad range of social enterprises and the risk of creating a situation where the criteria are so broad that access to CIC status is almost at will.

\section{(c) Finance}

In addition to the Community Interest Test, the other element identified in Enterprise for Communities as ". . . central to the CIC concept" ${ }^{49}$ is what is referred to as the asset lock. It is argued that it will be critical for acceptance of CICs by investors that there should be a commitment by CICs and those

profile Scottish charities (Moonbeams and Breast Cancer Scotland) were the subject of investigation by and subsequent court intervention at the behest of the Scottish Charities Office. See Scottish Parliament Official Report, Col 1955-1965, $24^{\text {th }}$ September 2003.

47 Enterprise For Communities: Proposals For A Community Interest Company, Report on the public consultation and the government's intentions, October 2003 (hereafter referred to as "The Report").

48 The Report, paras. 2.7 and 2.8.

49 Enterprise for Communities, para. 23 
who set them up to lock profits and assets into the company irrevocably. Clause 27 of the Companies Bill contains the mechanism whereby the asset lock is created. Again the mechanism adopted is the facility to create regulations which may:

“(a) prohibit or impose limits on the distribution of assets by community interest companies to their members, and

(b) impose limits on the payment of interest on debentures issued by, or debts of, community interest companies." 50

The intention also appears to be that the Regulator should be empowered by any such regulations to set any limits that may be required. The range of responses to the proposal to establish the asset lock was particularly diverse and in the Report the difficulties identified in striking an appropriate level of cap are reflected in the Government's decision not to deal with the matter in detail in primary legislation..$^{51}$ The principle of the asset lock is, however, entrenched within the present proposals and, subject, to the limits on distribution to be developed by the Regulator, there is no mechanism for disapplication of the lock so long as the company retains its CIC status. For those who are members or shareholders of a CIC it is unlikely that this will be a matter of concern. Their very purpose in adopting CIC status is presumably to pursue community objectives and not to maximise any form of return on their contribution to the company. A much more complex situation will prevail in respect of potential investors and lenders who have in contemplation investment in a CIC. The Regulator faces another difficult task in balancing the need to create an investment climate whereby the financial return to potential investors is sufficiently attractive to encourage investment, and the potentially conflicting desire to limit distributions from CICs with the intent of maximising the assets and capital available to further community activities. While CICs taking the form of a company limited by shares will be able to issue what are referred to in the Explanatory Notes to the Companies Bill as "investor shares" 52 and to make distributions to shareholders, the extent of any such distribution will be capped. If the cap is overly restrictive there is the risk that no new market will open up for potential investors and only those who are already motivated to invest in such activities and organisations on a largely philanthropic basis will find investment in CIC's attractive. If the cap is unduly lenient the market for investors may be larger but the resulting distinction between CICs and unregulated companies may be so minimal that those contemplating a new community venture may choose not to opt for CIC status, particularly given the increased regulatory burden associated with such status.

50 Companies Bill, clause 27 (1).

51 At paragraph 6.14 which outlines the Government's intentions on the cap it is stated that "The detailed workings of the cap will not be set out in primary legislation; the Government will set the structure of the cap in secondary legislation, and the CIC regulator will be responsible for setting the cap in a way that will balance the need to encourage investment with the primacy of community interest."

52 The Explanatory Notes (published electronically at <www.publications.parliament .uk/pa/ld200304/ldbills/008/2004008.htm> paragraph) simply refer to investor shares at paragraph 161 of the Notes as being "dividend paying ... The dividend payable on such shares will be subject to a cap". 
The position of creditors is also addressed in the proposals in the Companies Bill. Again, the mechanism adopted to regulate the distribution of assets on winding up of a CIC is the use of regulations. ${ }^{53}$ The Companies Bill and accompanying explanatory notes do not elaborate on how creditors may be treated but some guidance as to Government thinking may be found in the working paper on finance for CICs which accompanied Enterprise for Communities. Paragraph 9 of the working paper confirms the simple company law position which is that creditors of a CIC will have exactly the same rights as those of any other company. It is also stated that any residual assets remaining after payment of creditors will be safeguarded by the Regulator, carrying out a similar role to that undertaken by the Charities Commission in the winding up of charities. What remains unclear is what is likely to be the effect of any regulations of the type anticipated by clause 28 of the Companies Bill. The potential breadth of any such regulations is significant and the clause confirms that the regulations "(. . . may, in particular, amend or modify the operation of any enactment or instrument)." This wording would afford the possibility of a distribution mechanism which might differ from the conventional statutory distribution models recognised in respect of other companies in the United Kingdom. This proposal has within it a level of uncertainty which will be unwelcome to potential investors in and creditors of a CIC and will represent yet another factor which will be of significance in any assessment as to whether or not to become financially associated with a CIC.

In the consultation process the DTI also canvassed opinion as to whether CICs should be able to issue shares on which an uncapped dividend might be paid. The conclusion stated in Enterprise for Communities was that despite the possible attractiveness of this mechanism in opening up a wider range of finances "the use of real equity is contrary to the concept of the CIC profit and asset lock" 54 and that accordingly, CICs should not be able to issue shares that pay an uncapped dividend. The profit and asset lock is, therefore, at the very heart of proposals for the CIC. In the absence of availability of 'real equity' the capped equity which is proposed for CICs must be both sufficiently attractive to encourage external investors and adequately capped to secure ongoing financial needs of the CIC. Striking this balance will be a delicate task.

\section{(d) Governance}

The Companies Bill is largely silent on governance issues which were dealt with in some detail in Enterprise for Communities. Central to the original proposals was a desire that "all organisations should engage with their stakeholders for the long term health of their businesses." 55 The Government also anticipated that CICs would also "display a strong focus on stakeholder needs." 56 The fact that the Companies Bill makes no reference to these apparently key issues is a reflection of the strength of comment on the original proposals and the potential difficulties associated with the introduction of a stakeholder centred duty. The Government's intention to

53 Companies Bill, clause 28.

54 Enterprise for Communities, para.31.

55 Enterprise for Communities, para.33.

56 Enterprise for Communities, para.34. 
move away from the concept of stakeholder involvement was signalled in the Report. Citing the existence of "clear practical difficulties" 57 and "the lack of a consensus about the need for a statutory requirement" ${ }^{158}$ [to seek the views of . . . stakeholders] the Government is now apparently of the belief that CICs' annual reporting obligation on engagement with stakeholders and guidance from the Regulator on engagement with stakeholders will achieve most of the requirements that could have been obtained by statutory means, but in a less burdensome regulatory and practical environment.

By moving away from the original proposals for a statutory mechanism obliging engagement with stakeholders, potential problems of inconsistency with company law are removed. CICs will be companies established under existing UK companies legislation and it is apparently intended that their "directors . . . will have the same rights and duties." 59 Retention of the proposed stakeholder engagement mechanism would have given rise to a number of difficult issues in respect of the interaction of existing directors' duties and the stakeholder mechanism. Directors at present owe their duties to the members of their companies ${ }^{60}$ and even under the present proposals for a statutory statement of directors' duties ${ }^{61}$ that position remains unchanged. A statutory engagement mechanism would have placed directors of CICs in a position where their duties as directors were clearly not the same as those owed by directors of non-CIC companies. Other difficulties would have arisen from a statutory engagement mechanism. There would have been a fundamental problem for directors in the identification of the stakeholders for their CIC. The proposed statement of directors' duties set out in the White Paper is accompanied by notes which elaborate on material factors and matters which directors must consider in the observance of their duties, and these include:

"the company's need to foster its business relationships, including those with its employees and suppliers and the customers for its products or services". ${ }^{62}$

The original governance proposals in Enterprise for Communities did not elaborate on how stakeholders would be identified but did recognise that there could be difficulty in identifying such a group. ${ }^{63}$ Given the likely diversity of activity of organisations which might seek CIC status the range of potential stakeholders would have been equally diverse with the associated concern that directors of CICs would have had considerable difficulty identifying this group with any level of certainty. Even if the process of identification had been achievable directors and stakeholders would still have been uncertain as to how the duty of engagement would be fulfilled and enforced. No guidance was given in the original proposals for the CIC as to how this would be addressed. A final potential difficulty

57 The Report, para.9.12

58 The Report, para.9.12

59 Enterprise for Communities, para. 15.

60 The leading authority remains Percival v Wright [1902] 2 Ch.421.

61 The White Paper, Modernising Company Law (2002) Cm.5553-I, (hereafter referred to as "The White Paper") which followed the DTI's Company Law Review favoured a statutory statement of directors' duties.

62 The White Paper, Clause 19 and Sch.2.

63 Enterprise for Communities, para.35. 


\section{Northern Ireland Legal Quarterly [Vol. 55, No. 3]}

would have occurred had disputes arisen between the interests of investors qua members of the company, to whom duties would clearly have been owed in accordance with existing company law, and other stakeholders owed some form duty under the proposed engagement principle. In the absence of statutory guidance directors would potentially have been faced with very difficult issues had such disputes arisen.

Stakeholders still appear to be significant in the mind of the Government in relation to CICs but do not figure in the proposals contained in the Companies Bill. Two issues arise as a result. Firstly, the decision not to proceed with the statutory concept highlights the difficulty of deeming an existing body of law to be applicable, i.e. company law, and then attempting to graft on to that body of law concepts which at best rest uneasily and at worst in complete contradiction with that existing body of law. Secondly, the question arises as to how effective governance of CICs can be in respect of their dealings with stakeholders if such a core principle is not to have the benefit of statutory regulation. On this issue The Report comments as follows:

"Where a CIC does not make efforts to engage with its stakeholders, the community interest report will invite it to explain its reasons for not doing so. In effect, CICs will be encouraged either to comply with good practice in this area or to explain why they have not done so. The Government does not propose to introduce a legal requirement for CICs to give a detailed explanation in these reports of any decision not to follow good practice ... where a CIC decides to do nothing to involve its stakeholders and to offer no explanation for this in its report, the public nature of this report means that this decision will be clearly apparent to the community the CIC serves." 64

This approach to the governance of CICs and the interests of stakeholders is significantly weaker than that originally proposed. The principle of stakeholder engagement sits easily with the philosophy of community benefit which is so central to community interest companies. It may be the case that the revised approach to governance will operate effectively in the promotion of stakeholder interests but there are two issues to note. Firstly, it would remain open to directors of CICs to adopt what has in other contexts been referred to as a box-ticking ${ }^{65}$ philosophy in respect of their engagement with stakeholders. A simple affirmation in the community interest report that engagement had taken place with stakeholders may be deemed by directors of a CIC to be sufficient evidence of their engagement. Secondly, reliance upon "the community the CIC serves" 66 is hardly a robust or obviously enforceable governance mechanism and it is not obvious what course of

64 The Report, para.9.13.

65 For a good general discussion of the approach by Boards of Directors to compliance statement obligations see C.A. Belcher, "Regulation by the Market: The Case of the Cadbury Code and Compliance Statement", [1995] J.B.L 321342 .

66 The Report, para.9.13. 
action such a community might take were it to be unhappy with the actions of a CIC and its board.

The other significant governance proposal outlined in the original proposals for the CIC was some form of limitation on the power that might be exercised by investors over the control of CICs. Although the Companies Bill is again silent on this issue the Government's intention in this area is to limit investor voting rights to below twenty five per cent of the total, with scope for greater voting rights on matters which specifically affect the value of their shares. ${ }^{67}$

\section{(e) Regulation}

Central to the CIC is the role of the officer to be known as the Regulator of Community Interest Companies. ${ }^{68}$ Recognising concerns expressed in the consultation process over the potential for burdensome regulation, the Companies Bill attempts to outline how the Regulator will discharge the functions to be exercised in respect of CICs. The philosophy appears to be based upon a light touch approach and in exercising regulatory functions the Regulator must have regard to:

"(a) the likely impact on those who may be affected by the discharge of those functions,

(b) the outcome of consultations with community interest companies and others with relevant experience, and

(c) the desirability of using resources in the most efficient and economic way." ${ }^{69}$

The functions to be undertaken by the Regulator will include vetting that applicants for CIC status satisfy the community interest test, ${ }^{70}$ reviewing and publishing community interest reports ${ }^{71}$ and dealing with the disposal of residual assets of wound-up CIEs. ${ }^{72}$ The Regulator will also have extensive powers to investigate CICs, to appoint and remove directors, to appoint a manager to run the affairs of a CIC and to vest property in an Official Property Holder. ${ }^{73}$ Unfortunately, there is no guidance as to the identity of the Regulator. Given the CIC's proposed identity as a company there are strong arguments to the effect that the Regulator should be the Registrar of Companies. Conversely, now that Industrial and Provident Societies (which often operate and provide services similar to those anticipated in respect of CICs) are regulated by the Financial Services Authority it can be argued that CICs should also be regulated by the FSA. To use either existing body raises issues of significance. While the Registrar of Companies has historically exercised a wide range of regulatory powers in respect of companies it would be a significant move to afford the Registrar the range of investigatory powers which are proposed in respect of CICs. Using the FSA as the

67 The Report, para.10.9

68 Companies Bill, clause 24(1). Hereafter referred to as "the Regulator".

69 Companies Bill, clause 24(4).

70 Companies Bill, clause 33(4).

71 Enterprise for Communities, para.41.

72 Enterprise for Communities, para.41.

73 Companies Bill, clause 39 to 45. 
regulatory body would give rise to an altogether different concern that the regulatory approach it might adopt would not sit easily with the light touch approach which is anticipated in the Companies Bill.

In structural terms the approach adopted in the CIC regulatory model is in the broadest of terms similar to that used in respect of charities in England and Wales. Under that model the Charities Commission deals with, inter alia, recognition and registration ${ }^{74}$ of charities and exercises an ongoing supervisory role with powers of investigation and management. ${ }^{75} \mathrm{~A}$ fundamental issue relating to the adoption of such a regulatory model is whether the very existence of that regime will act as a disincentive to adopt the form. There is no directly parallel financial gain associated with CIC status such as the tax relief associated with charitable status, yet a regulatory regime is proposed which in many respects parallels the charitable regime (albeit with what is intended to be a light touch). Whether the existence of the regulatory regime proposed for CICs will be seen as reassuringly attractive to potential investors and a price worth paying for those adopting the form or an unnecessary and heavy handed burden remains to be seen.

\section{PROGRESS OR CONFUSION?}

The LLP has been the subject of criticism on the basis of an absence of clarity and certainty. The absence of clarity relates to the very rationale for the LLP and the form adopted and the absence of certainty relates primarily to the potential impact on creditors of hybrid mechanisms and provisions based on new and existing legal structures. The CIC can also be assessed by reference to measures of clarity and certainty.

\section{Clarity}

The proposals for the CIC differ fundamentally from those which led to the introduction of the LLP in that they do not have their origin in a campaign by an interest group which has identified the need for a remedy for a perceived wrong. Proposals for a CIC have not been at the very top of the agenda of groups campaigning for reform in the broader not-for-profit sector. The CIC has emerged from the present Government's proposals for reform and change in the charitable and not-for-profit sectors. The proposals for a CIC are largely uncontroversial and are not intended to remedy any form of glaring wrong in existing legal provision. It also seems unlikely at present that the CIC will become a legal form of major significance in terms of numerical take up. ${ }^{76}$ It is a form designed for a very specific purpose.

The proposals for the introduction of a CIC have been broadly welcomed ${ }^{77}$ and there are positive elements which may be contrasted with the LLP.

74 Charities Act 1993, s.3.

75 Charities Act 1993, Parts III and IV.

76 The Regulatory Impact Analysis ("RIA") which accompanied the Bill (DTI, URN $03 / 1606$, December 2003) suggests that that “. . . our working assumption is that initially there may be between 100 and 300 new CICs registering each year (RIA. Paragraph 4.7 at page 92 ).

77 A total of 122 responses were received in respect of the first proposal in Enterprise for Communities, which was the intention to legislate for CICs when 
While the decision to adopt an existing corporate form may be prudent the reasoning for the adoption of the company is superficial and none of the elements of the consultation process have involved what could be considered as an in-depth evaluation of alternative structures. ${ }^{78}$ Nonetheless, the outcome does have the benefit of adopting a form which is generally well understood and, predominantly in the form of the company limited by guarantee, already extensively used in the not-for-profit sector. The twin aims of securing limited liability for those involved in promoting and running the organisation and locking in finance to the objectives of the organisation are arguably achieved by the CIC. While the regulatory regime associated with CICs will initially be new and unfamiliar, clarity will exist in the form of existing rules and principles of company law. What may be less clear for those contemplating which form of organisation to adopt for their non-for-profit activity is whether the CIC is the ideal form. There are issues here which are remarkably similar to those which arose in respect of the LLP which was introduced at a time when reviews of both partnership and company law were being undertaken. The CIC is being introduced at a time when considerable change is underway or in contemplation in respect of much of the not-for-profit sector. The regulation of industrial and provident societies is being modernised ${ }^{79}$ and bills are being prepared which will contain proposals for significant reform and change for charities. ${ }^{80}$ It is in respect of the overlap with charitable organisations where clarity becomes particularly significant. Central to the proposals for CIC is the concept of community benefit and the test to be administered by the Regulator. While it has been indicated that the test will be wider in application than the existing charitable public benefit test that test will almost inevitably be the subject of attention in the anticipated changes in charity law. If there is change in the overall definition of charity, with possible change in the existing public test this may have a consequential effect on how the Regulator interprets the community benefit test. The provisions in the Companies Bill also give rise to issues in respect of the overlap. Clause 23(3) specifies that "A community interest company established for charitable purposes. . . is to be treated as not being a charity". While the intention behind this proposal may be to improve certainty and remove confusion in the mind of the public as to the nature of a CIC in fact the overall effect may lead to even greater confusion. ${ }^{81}$ There

Parliamentary time permitted. $77 \%$ of those proposals were deemed to be in support of the proposals, 9\% against and 14\% neutral (The Report, page 5).

78 Enterprise for Communities spends only four pages (pp.10-14) considering alternative structures and making the case for the use of a company.

79 The first stage of the modernisation process is The Industrial and Provident Societies Act, 2002. which states in the preamble to the Act that "An Act to enable the law relating to societies registered under the Industrial and Provident Societies Act 1965 to be amended so as to bring it into conformity with certain aspects of the law relating to companies..."

80 For an indication of the likely proposals to be contained in any Bills which may be promulgated this year see Private Action, Public Benefit, n.3 supra and in Scotland as referred to at n.46, supra.

81 During the debate on the second reading of the Companies Bill Lord Phillips of Sudbury commented that ". . . we will then have the bizarre state of affairs whereby the type of company most distant from that which the public conceives of as a "charity"- namely, a typical company limited by shares, which is the standard 
exists the possibility that a body, with entirely charitable purposes by having opted to register as a CIC, may not be charity. There is no obvious justification for this clause and it must be uncertain how it will be construed and applied, particularly in respect of tax law. It is unclear for tax purposes how a CIC is to be treated when it has exclusively charitable purposes. In the absence of any convincing arguments for the restriction proposed in clause 23(3) it would be more appropriate to permit CICs to be charities where their constitutions are appropriately drafted to take account of matters such as asset distribution. If clause 23(3) is retained two further issues arise. Firstly, and particularly in respect of those contemplating the creation of a new organisation as opposed to those contemplating a change in legal form, there will need to be clear guidance both from the Registrar and the regulators of charities as to the respective merits and regulatory regimes in both areas when the purposes of the anticipated organisation are charitable. While the CIC may be attractive in being the only form available for what appears to be a community interest project, limited liability can also be obtained through the use of a company limited by guarantee for an organisation which is recognised as a charity. Promoters of an organisation with clearly charitable purposes will still be faced with the potentially confusing and difficult task of deciding whether to pursue community interest or charitable status. The second issue relates to public perception. If an organisation has purposes which are clearly charitable but it is in fact a $\mathrm{CIC}$, it is not clear that members of the public or third parties dealing with such an organisation will in fact draw or indeed be readily able to draw a distinction between community status and charitable status. It is unclear what accidental and unanticipated consequences this may have for CICs with charitable purposes which may in fact be perceived to be and treated as if they were charities. The position may become even less clear if any amended definition of charity and charitable status which flows from the charity law reform proposals in contemplation, places more reliance on language which emphasises public benefit.

\section{Certainty}

Criticisms of the LLP in respect of certainty were largely focussed on the impact on creditors and the willingness of lenders to lend on terms no less favourable to those made available to other organisational forms. Much of the uncertainty identified arose as a result of the application of a mixture of rules and principles from partnerships and company law. The CIC will not suffer from this difficulty. It will not be an entirely new legal form in the unique sense of the LLP. Existing rules of company law will apply to the CIC. There are, however, questions as to how relevant and applicable certain of those existing rules may be in respect of CICs. The applicability of section 214 of the Insolvency Act 1986 is an example. It is questionable whether this section should apply in respect of CICs. A combination of the proposed asset lock and scrutiny by the Regulator arguably provides a level of protection to investors which does not require the additional support of the

vehicle for a private benefit business - will continue to be permissible as a vehicle for a charity, while a CIC - expressly a community interest company with controls on the distribution of its assets - cannot be used as a vehicle for a charity. That is extremely confusing." Hansard, Col 277, 8 ${ }^{\text {th }}$ January 2004. 
contribution mechanism contained in section 214. Generally, however, it appears that the decision to recognise the CIC as a company subject to existing company law means that it is less likely that the CIC will encounter difficulties arising from the interaction of differing legislative and common law regimes such as those which have been identified in relation to the LLP. It remains in the area of overlap with charities where substantial confusion and uncertainty certainty is likely to arise.

\section{CONCLUSION}

The proposed creation of the CIC is entirely consistent with the DTI's broad aim of providing ready access to corporate form and the protective nature of limited liability status. The CIC also appears to provide a vehicle which will protect investment made for a clearly community based purpose. Unfortunately, the proposals also give rise to fundamental difficulties which may adversely impact on the attractiveness of the CIC and give rise to even greater confusion for those faced with choosing from an even broader range of legal forms for their chosen activity than has hitherto existed. Lessons have not been learned from the process which led to the creation of the LLP. Uncertainty for creditors of an LLP has been identified as a consequence of that process. For those seeking limited liability status, particularly those with charitable purposes, the CIC will be another option but the process of identifying which form to adopt will be more complex than ever. The issue of uncertainty in respect of which the LLP has been the subject of considerable criticism is also evident in respect the CIC. On this occasion the focus of the uncertainty is not directly related to creditors of the organisation and the potential impact of a potentially confused hybrid legal regime, but in respect of those who are faced with the even more fundamental decision as to which legal form to adopt. With the likelihood of yet further choice to follow in the legal forms available to the broader notfor-profit sector, the need for clear guidance and support for those seeking to make an informed and appropriate choice will never have been greater. The present proposals for the CIC may very well be suited to the needs of a small group of organisations who are clear in their focus and direction. For organisations which may already have objects and purposes which are 'charitable' even although they may not be registered or recognised charities, the proposed construction of the CIC may not be an attractive route to limited liability. 